\title{
К ВОПРОСУ О ГЕНЕЗИСЕ ПСЕВДОТАХИЛИТОВ
}

\section{Морозов Ю.А., Матвеев М.А., Смульская А.И., Кулаковский А.Л.}

Институт физики Земли им. О.Ю. Шмидта РАН, Москва, тогоzov@ifz.ru

Генезис псевдотахилитов, несмотря на столетнюю историю их изучения со времен первого описания [8], до сих пор вызывает дискуссии [7,10,11,12]. С учетом пространственного совмещения с импактными структурами, типа Вредефорт, в качестве первопричины формирования этого темного афанитового материала жильных форм обособления рассматривается шоковое ударное воздействие и распространение в массиве пород упругого волнового фронта [6], приводящее к дезинтеграции и остеклению породного матрикса. Их приуроченность к активным сейсмогенным разломным зонам позволяет ряду исследователей отдавать предпочтение фрикционному расплавлению с образованием стекловатой массы, включающей обломки минералов и пород окружающего субстрата [7]. Не менее часто главная роль в их генезисе отводится хрупкому, чисто механическому разрушению породы в зонах разрывов с образованием измельченной, вплоть до наноразмерности, обломочной непрозрачной матрицы типа микрокатаклазита [12]. Вместе с тем, достаточно широко распространены мнения, допускающие в том или ином виде совмещение или комбинацию описанных процессов, предполагая для псевдотахилитов полифакторную природу или разный генезис в зависимости от реальной геологической обстановки [5]. Более того, есть мнение, что морфогенетические разности, связанные с дроблением, расплавлением и шоковым упругим воздействием представляют собой продукты разных стадий единого процесса преобразования пород в зависимости от скорости воздействия и, таким образом, генетически связаны [11].

В рамках проблемы изучения особенностей режима сейсмической подвижки в очаговых зонах по продуктам преобразований пород в разломах предполагаемой сейсмогенной природы [3] нами были исследованы псевдотахилиты в двух районах Фенноскандии - на баренцевоморском побережье Кольского полуострова (п-ова Рыбачий-Средний) и в Северном Приладожье.

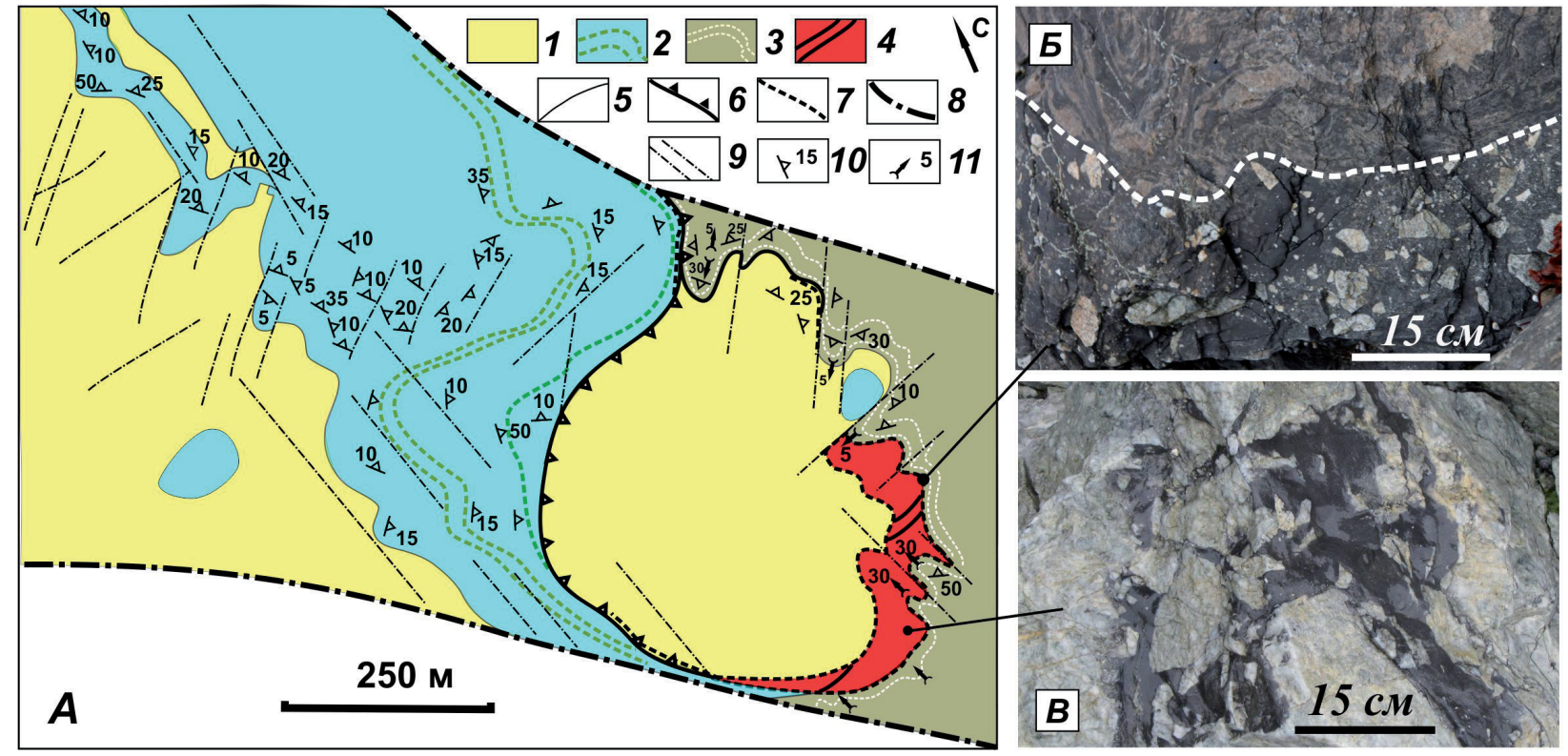

Рис. 1. Детальная схема строения мыса Вестник на перешейке между полуостровами Рыбачий-Средний и фото псевдотахилитовых образований в обнажениях.

1-3 - рифейские отложения: 1 - 1 - полимиктовые валунники и конгломераты; 2 -кварцито-песчаники с прослоями черных алевролитов в них; 3 - чередование тонкослоистых серо-зеленых песчаников и черных алевролитов; 4 - катаклазированные плагиограниты с дайками базитов; 5 -стратиграфические контакты; 6 - задокументированные разрывы; 7 - контакты, отмеченные псевдотахилитами; 8 - магистральные разломы шовной зоны; 9 - дешифрируемые разрывы; 10 - элементы залегания слоистости; 11 - шарниры складок. 
Псевдотахилиты в рифейском комплексе полуостровов Рыбачий-Средний, впервые были обнаружены и описаны в зоне разлома Тролльфиорд-Рыбачий-Канин [1], разделяющего эти полуострова и трассирующего зону взаимодействия Восточно-Европейского кратона и Западно-Арктической платформы. Они маркируют контакты тектонической пластины архейских пород, внедренной в разрез рифейских турбидитов (мыс Вестник) и представляют собой ветвистую систему прожилков черного афанитового материала в катаклазированных гранито-гнейсах и гранитоидах (рис. 1). Их микроскопическое и микрозондовое обследование (рис. 2 А) не показало видимых признаков плавления афанитового вещества, имевшего на всех масштабных уровнях рассмотрения мелкообломочную структуру, что свидетельствует в пользу варианта чисто механического дробления породы по типу катаклаза. Для формального подтверждения этого была применена методика фиксации различий между механически раздробленным субстратом и матрицей, испытавшей процессы частичного расплавления [9] через оценку характера распределения размерности обломков в афанитовом матриксе. Исходя из фрактального характера фрагментирования породы ожидается, что в случае ее чисто механического дробления, такое распределение имеет нормальный логарифмический характер, отмеченный обобщающей прямой с наклоном, соответствующим коэффициенту фрактальности. Анализ распределения обломов по размерности в псевдотахилитах мыса Вестник с использованием программы «imageJ» показал нормальное логарифмическое распределение на всех тестированных участках (рис. 2 Б), указывая на высокую вероятность чисто механического дробления породы в разломе. Это, правда, не исключает варианта локального проявления процессов подплавления, но свидетельствует о явном доминировании процессов катаклаза при внедрении тектонической платины гранитоидов.

Еще одним косвенным свидетельством в пользу варианта механического измельчения породы, которое происходило в явно приповерхностных уровнях коры, без значительных минеральновещественных преобразований, стал факт практически полной идентичности химических составов матрицы псевдотахилита и вмещающего его гранита по основным минералообразующим элементам (рис. 2 В).
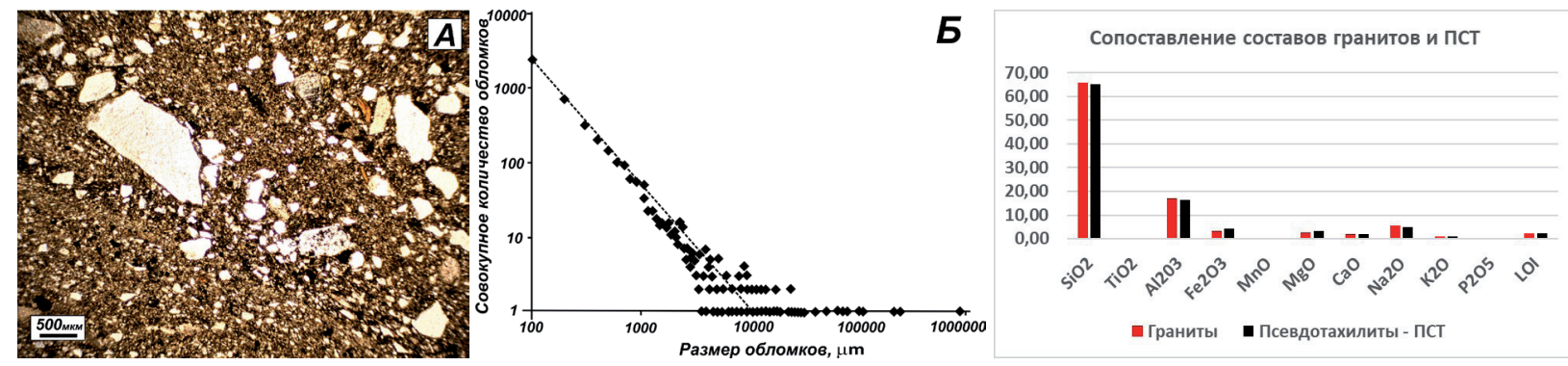

Рис. 2. Микрообломочная структура псевдотахилитов мыса Вестник (А), нормальный логарифмический характер распределения его обломков (Б) и результат сопоставления химических составов матрицы псевдотахилита и вмещающих гранитоидов (B).

Заметно иная ситуация выявляется в псевдотахилитах по метатерригенным породам палеопротерозойской ладожской серии (Северное Приладожье). Там псевдотахилитовые прожилки обычно приурочены к наиболее поздним разрывным нарушениям, секущим все предшествующие деформационно-метаморфические структуры уровня силлиманит-мусковитовой субфации (рис. 3 А) и, вероятно, маркируют этап наложенных хрупких деформаций, уже связанных с орогенным этапом развития региона.

Здесь выявляется заметно иной облик обломочной матрицы с признаками ее течения и полосчатого строения, схожими с флюидальностью лав (рис. 3 А, Б), а сама матрица, бурая по цвету, визуально напоминает вулканическое стекло, измененное процессами витрификации. Но наиболее существенна заметная округлость обломков (рис. 3 Б), очевидная сглаженность углов и редкость остроугольных фрагментов. Важно и то, что эти округлые формы не всегда бывают мономинеральными, 

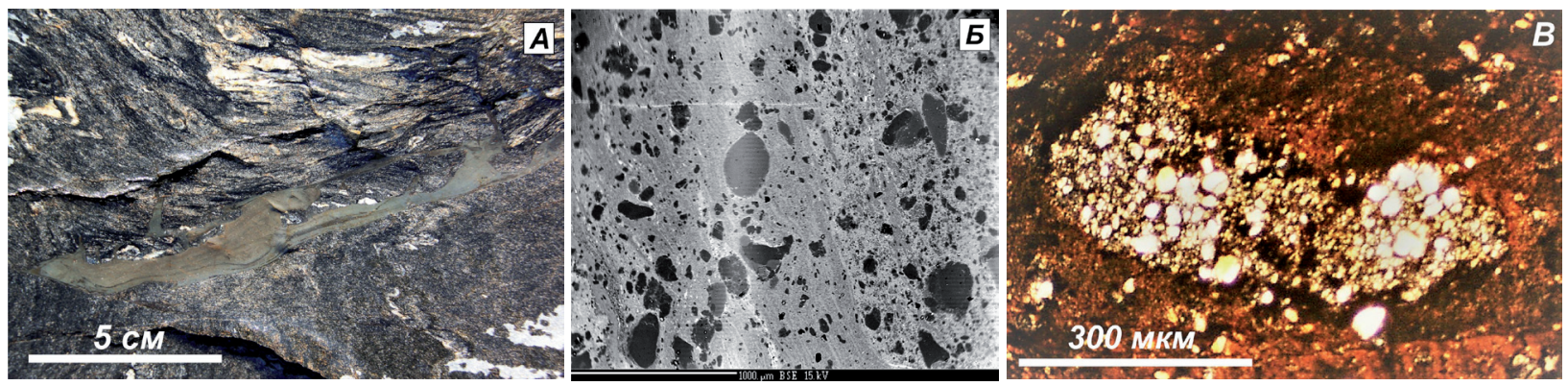

Рис. 3. Псевдотахилиты Северного Приладожья с признаками плавления породного субстрата: флюидальностью (А), округлостью обломков (Б) и резорбированием стеклоподобной матрицей фрагментов породы (В).

а довольно часто представляют собой породный агрегат минералов, частично резорбированным бурым стеклоподобным материалом (рис. 3 В), т.е. реформированию с очевидным участием процессов плавления, подвергались фрагменты породы. В отдельных ветвях псевдотахилитовых прожилков довольно часто наблюдается образование новых минералов по афанитовой матрице, обычно представленных ориентированными «потоками» слюдистого материала. Измеренный на микрозонде состав этих новообразований оказался близким мусковитам, однако, судя по содержанию межслоевых катионов (K, Na, Ca) между 88-94 \%, они, вероятно, гидратированы, или могут быть переходными разностями к иллитам. Т.е. стеклоподобный матрикс витрифицировался явно в более приповерхностных условиях по сравнению с уровнем преобразования исходных вмещающих пород.

В пользу участия процессов плавления в формировании этих псевдотахилитов свидетельствую также результаты морфометрического анализа обломочных фрагментов матрикса. Статистический характер распределения разноразмерных обломочных фрагментов показал явное отклонение (искривление кривой) от нормальной логарифмической последовательности (рис. 4 А), указывающее на уменьшение количества малоразмерных обломков, начиная с рубежа 700-800 микрон, и позволяющее связывать это с их растворением в расплаве $[4,9]$. Такой же вывод о присутствии расплава в афанитовом матриксе можно сделать и на основании оценки степени округлости обломочных фрагментов в соответствии с формулой $R_{d}=\Sigma(r i / R) / n$, где $r i-$ радиус кривизны в одном из углов обломка, $R$ - радиус максимальной вписанной внутри класта окружности, $\mathrm{n}$ - число измеренных углов класта в данном сечении. С помощью такого подхода было эмпирически установлено [4], что параметр округлости $<0.4$ характерен для обломков катакластической природы, а $>0.4$ - для псевдотахилитов, возникших с участием плавления. Для нашего случая этот параметр оказался больше 0.6 (рис. 4 Б).

Еще более убедительным аргументом в пользу расплавной природы рассматриваемого псевдотахилита можно считать результат сопоставления его химического состава с составом вмещающих метапсаммитов (рис. 4 В), которое показало заметное обогащение первого кремнием и натрием при уменьшении содержания калия, алюминия, и магния. Тенденцию обогащения можно следствием растворения в расплаве мелких фрагментов плагиоклаза и кварца, в то время как обеднение калием иногда связывают с его испарением при плавлении в открытой системе [2]. Изменение содер-
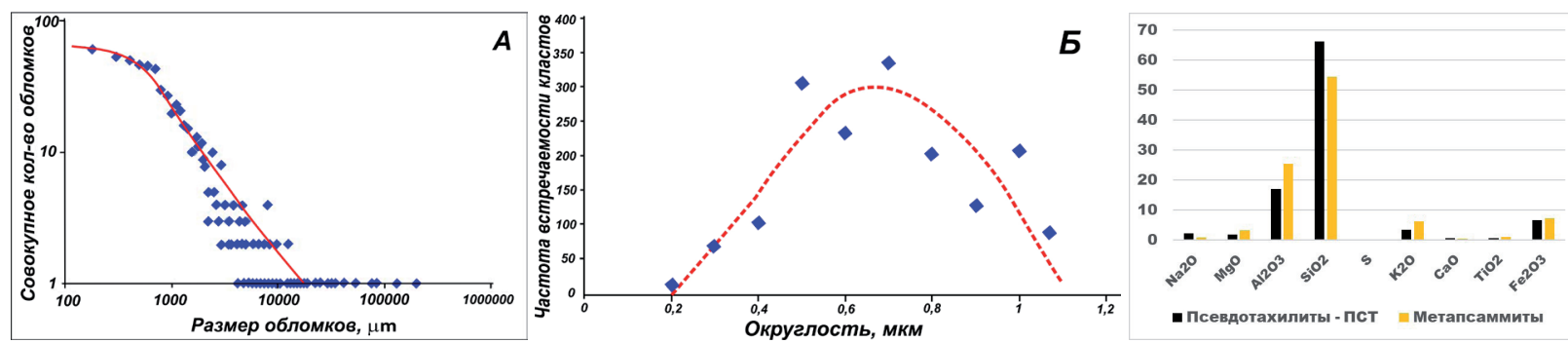

Рис. 4. Свидетельства расплавной природы псевдотахилита Северного Приладожья: (А) распределение размеров обломков; (Б) параметр округлости оплавленных фрагментов; (В) сопоставление химических составов псевдотахилитов и вмещающих их метапсаммитов. 
жания магния и алюминия требует специального изучения, хотя и допускается их связывание в новообразованные слюды, которые в силу неоднородности их роста в матрице псевдотахилита, могли не попасть (или попасть только частично) в проанализированный объем изученного образца.

Таким образом, изучение этих двух разновидностей псевдотахилитов показало, что они принадлежат к двум разным генетическим формам, образованным преимущественно механическим измельчением породы (Рыбачий-Средний) и ее частичным плавлением (Северное Приладожье). С учетом результатов экспериментального воспроизведения псевдотахилитов при сейсмических скоростях сдвига [11], показавших, что измельчение и фрикционное плавление являются взаимодополняющими, а не взаимоисключающими процессами, и образованию расплавного псевдотахилита обязательно предшествует стадия механического измельчения породы, можно воспринимать рассмотренные нами как результат проявления разных стадий единого процесса преобразований вещества в зоне динамической подвижки, предположительно сейсмогенной природы.

Работа выполнена в рамках ПФНИ Президиума РАН І.1.19. «Фундаментальные проблемы геолого-геофизического изучения литосферы» и частично по теме № 0144-2014-0089 госзадания ФБГУН ИФЗ РАН.

\section{Литература}

1. Балуев А.С., Морозов Ю.А., Терехов Е.Н., Баянова Т.Б., Тюпанов С.Н. Тектоника области сочленения Восточно-Европейского кратона и Западно-Арктической платформы // Геотектоника. 2016. № 5. C. 3-35.

2. Горностаева Т.А. Микро- и нанонеоднородность земных и лунных импактных стёкол // Диссертация на соискание учёной степени доктора геолого-минералогических наук. М.: ИГЕМ РАН. 2017. 290 с.

3. Морозов Ю.А., Смульская А.И., Кулаковский А.Л., Матвеев М.А. Структурно-вещественные записи палеоземлетрясений в терригенных породах: анализ и интерпретация // Физика Земли. 2018. № 1. С. 3-25.

4. Lin A. Roundness of clasts in pseudotachylytes and cataclastic rocks as an indicator of frictional melting; J. Struct. Geol. 1999. V. 21(5). P. 473-478.

5. Lin A. Fossil Earthquakes: The Formation and Preservation of Pseudotachylytes / Springer-Verlag, Berlin Heidelberg. 2008. 348 p.

6. Martini J. E. J. The metamorphic history of the Vredefort dome at approximately $2 \mathrm{Ga}$ as revealed by coesitestishovite-bearing pseudotachylites // Journal of Metamorphic Geology. 1992. V. 10. P. 517-527.

7. Maddock R. H. Melt origin of fault-generated pseudotachylytes demonstrated by textures // Geology. 1983. V. 11. P. 105-108.

8. Shand S. J. The pseudotachylyte of Parijs (Orange Free State), and its relation to «trap-shotten gneiss» and «flinty crush-rock» // Geological Society of London Quarterly Journal. 1916. V. 72. P. 198-221.

9. Shimamoto T., Nagahamo H. An argument against the crush origin of pseudotachylytes based on the analysis of clast-size distribution // Journ. Struct. Geol. 1992. V. 14. N. 8/9. P. 999-1006.

10. Sibson R.H. Generation of pseudotachylyte by ancient seismic faulting // Royal Astronomical Society Geophysical Journal. 1975. V. 43. P. 775-794.

11. Spray J.G. Pseudotachylyte controversy: Fact or friction? // Geology. 1995. V. 23. N. 12. P. 1119-1122.

12. Wenk H. R. Are pseudotachylites products of fracture or fusion? // Geology. 1978. V. 6. P. 507-511. 